A review of workplace physical activity interventions

\title{
A systematic review of workplace health promotion interventions for increasing physical activity
}

\section{Abstract}

Purpose: The benefits of an active lifestyle are widely documented yet studies show that only a small proportion of adults engage in sufficient levels of physical activity. The workplace presents an ideal avenue for delivering initiatives to promote physical activity; overcoming commonly cited barriers such as a 'lack of time' and providing access to a large intersection of society. The purpose of this study was to a) explore the types of interventions workplaces implement to promote physical activity among staff, b) describe the characteristics of those interventions, c) understand if these interventions positively impact on activity levels, and d) assess the methodological quality of studies. Methods: A systematic review of workplace physical activity interventions published up to April 2011 was conducted to identify types of interventions and their outcomes.

Results: Of the 58 studies included, the majority utilised health promotion initiatives. There were 6 physical activity/exercise interventions, 13 counselling/support interventions, and 39 health promotion messages/information interventions. 32 of these studies showed a statistically significant increase in a measure of physical against a control group at follow-up.

Conclusions: While the studies included in this review show some evidence that workplace physical activity interventions can be efficacious, overall the results are inconclusive. Despite the proliferation of research in this area there is still a need for more well-designed studies to fully determine the effectiveness of workplace interventions for increasing physical activity and to identify the types of interventions that show the most promise.

Keywords: Systematic review, physical activity, exercise, workplace/ worksite intervention, health promotion, employee well-being. 


\section{Background}

The benefits of an active lifestyle are widely documented in the literature and current public health guidelines recommend that healthy adults engage in a minimum of 150 minutes of moderate to vigorous intensity physical activity every week [Department of Health, 2011; World Health Organisation, 2012]. Engaging in regular physical activity is important for both the physical and psychological well-being of people of all ages [Warburton et al., 2006]. Physical inactivity is a significant risk factor for the development of preventable chronic diseases such as coronary heart disease, stroke and type 2 diabetes [Fine et al., 2004; Jeon et al., 2007; Mora et al., 2007]. Regular physical activity helps to reduce body mass index and can serve a rehabilitative purpose; helping with the management of musculoskeletal disorders [Banbury et al., 2010; Department of Health, 2009]. Furthermore, research suggests that an active lifestyle may reduce the risk of premature death by around $20-30 \%$ [Department of Health, 2004]. Physical activity is increasingly recognised for its mental health benefits with several studies showing that engaging in regular physical activity can reduce the symptoms of depression and anxiety, improve mood, and aid stress management [Blake et al, 2009]. There is also an associated economic benefit, as the combined cost of treating preventable illnesses and the loss of working days due to sickness absence, across the global is substantial [Department of Health, 2009; Katzmarzyk \& Janssen, 2004; Medibank, 2007; Oldridge, 2008].

Despite the recognised health benefits of regular physical activity, studies from across Europe show that only a small proportion of adults engage in sufficient levels of physical activity [Dugdill et al, 2008]. For example, a study conducted across the European Union found that two thirds of the adult population did not reach the recommended levels of physical activity (Sjöström et al, 2006). Similarly, data from the UK reveals that only $39 \%$ of men and $29 \%$ of women meet government recommendations (NHS, 2008). Promoting regular exercise is thus crucial for societal 
health and well-being, as well as economic benefit and increasing physical activity is a significant public health issue for governments around the globe.

Public health policy worldwide has emphasised the need to create a culture that is conducive to regular physical activity [Department of Health, 2005; US National Physical Activity Plan, 2010; Department for Work \& Pensions \& Department of HSE; NICE, 2008]. Specifically, employers are encouraged to play a key role in promoting the health and well-being of working age adults [Department of Health, 2008; Department for Work and Pensions, 2008; NHS, 2008; World Health Organisation/ World Economic Forum, 2008]. It is argued that investing in the health of employees will have a multitude of benefits including reduced sickness absence, increased staff retention and better productivity [NHS, 2008; Proper et al., 2003]. From a public health perspective, the workplace presents an ideal avenue for the delivery of initiatives to promote physical activity; overcoming commonly cited barriers such as a 'lack of time' and providing access to a large and diverse intersection of society [Dugdill et al., 2008]. Against this backdrop, several published papers have reviewed the effectiveness of health promotion in the workplace. An early meta-analysis of worksite physical activity interventions, found that there was limited evidence for an increase in physical activity [Dishman et al, 1998]. Furthermore, the majority of studies included in this early review were deemed to be of poor scientific quality [Dishman et al, 1998]. A more recent metaanalysis by Abraham \& Graham-Rowes (2009) revealed that overall, worksite interventions had small positive effects on physical activity. The authors suggested that more recent interventional studies should be better designed. Similarly, in a systematic review of worksite physical activity interventions [across Europe, Australia, New Zealand and Canada], Dugdill et al., (2008) found some evidence that workplace walking and workplace counselling interventions positively impacted upon physical activity behaviour. They also emphasised the need for more well-designed studies to be conducted.

Given the increasing emphasis on the workplace as a key setting for the promotion of health, and the known benefits of physical activity on health, it is important to understand how physical 
activity is being promoted in workplace health promotion programs and to understand what effects, if any, they have on the physical activity levels of employees. The purpose of the present paper is therefore to complement and broaden knowledge gained from existing reviews of worksite physical activity interventions by providing an up-to-date overview of research studies in this area. Specific objectives include to a) explore the types of interventions workplaces implement to promote physical activity among staff, b) describe the characteristics of those interventions (e.g. sample size/ demographics, type of intervention, physical activity measures, theoretical underpinnings), c) understand if these interventions positively impact physical activity levels, and d) assess the methodological quality of studies. Based on the findings, we present a summary of what is known about the current state of worksite physical activity intervention research and ideas about directions for future research and practice.

\section{Methods}

\section{Literature search}

The following electronic databases were searched for studies that assessed workplace health promotion interventions' influence on levels of physical activity: Medline (1950-2011), Embase (1980-2011), Cinahl (1982-2011), PsychINFO (1950-2011), The Cochrane Library (Issue 4, 2011) and the National Research Register (Issue 4, 2011). A broad search strategy was developed using a combination of the search terms: Physical activity, Exercise, Health Promotion, Work, Worksite, Workplace, Employee, Employees (Figure 1). Peer-reviewed studies published in English up to $1^{\text {st }}$ April 2011 were retrieved. In addition, the reference lists of included studies and related systematic and non-systematic review articles were manually checked for further relevant articles.

\section{Study inclusion and exclusion criteria}

Studies were included in the review if they met the following inclusion criteria: 
1. Reported outcomes of an intervention study designed to increase energy expenditure amongst employees

2. Conducted in a workplace setting

3. Included an outcome measure assessing level of physical activity

4. Employed a randomised controlled trial $(\mathrm{RCT})^{1}$, prospective randomised trial $(\mathrm{PRT})^{2}$, or quasiexperimental design ${ }^{3}$

Studies that did not meet these criteria were excluded from the review. In addition, studies that only included employees with an existing health problem (e.g. cardiovascular disease, neck problems etc.) or were published in a non-English language journal were also excluded from the study. There were no restrictions on the basis of sample size, participant characteristics (e.g. age, gender etc.), type of intervention, study length or duration of follow-up. Studies were eligible for inclusion if an intervention group was compared with either: an untreated comparison/ control or another intervention group. Quasi-experimental studies and PRTs were included in addition to RCTs, as it is acknowledged that a true randomised controlled trial design might not always be possible in a workplace setting. Multi-component health promotion interventions, where the main objectives were to improve general health practices or reduce $\mathrm{BMI}$, were included in the review as long as they reported an outcome measure specifically related to participants' levels of physical activity. Two researchers independently reviewed all potentially relevant articles identified from the literature search for eligibility. Any disagreements between them were resolved by discussion.

\section{Data extraction and quality assessment}

The final sample of selected studies were reviewed by the lead author, who extracted data on the sample characteristics, intervention and study design, measures used to assess physical

\footnotetext{
${ }^{1}$ A study in which people are allocated at random to one of several interventions groups. One of these groups is the standard of comparison or a control.

${ }^{2} \mathrm{~A}$ study in which people are allocated at random to one of several intervention groups. These intervention groups are compared with each other and there is no control group.

${ }^{3}$ An experimental study similar to a randomised controlled trial, except there is no random assignment of participants to groups.
} 
activity, and the results of each paper in relation to physical activity outcomes. Data were reported using standardised data extraction forms recommended by the Scottish Intercollegiate Guidelines Network (SIGN) (2011). Methodological quality of each study was then assessed independently by two reviewers using a checklist adapted from an earlier systematic review of workplace weight loss interventions (Benedict \& Arterburn, 2008) and recommendations from the SIGN (2011). Additionally, the present review used the taxonomy of behaviour change techniques developed by Michie et al. (2011) to code the specific strategies and techniques used in the interventions to promote physical activity.

\section{Results}

\section{Included studies}

A total of 58 studies met the inclusion criteria. Details regarding the process followed in the review and selection of the studies is presented in Figure 2. Following selection, studies were grouped into three types of intervention: 1) Physical activity/exercise interventions (including interventions such as active travel, stair walking interventions and exercise classes) $(n=6) ; 2)$ Counselling/support interventions (including telephone counselling/coaching, motivational interviewing, peer support and group-based counselling/coaching interventions) ( $n=13) ; 3)$ Health promotion messages/information interventions (including interventions such as health checks/screening, the delivery of health promotion messages/information via email, posters, flyers, information classes, internet etc. and multi-component health promotion programmes $(n=39)$. For each intervention type, we report the characteristics of the studies (e.g., sample size, population, recruitment, use of theory), reported impact on physical activity levels, and a quality assessment.

\section{Physical activity/exercise interventions}

Six of the studies were categorised as physical activity / exercise interventions [see table 1]. 


\section{Study characteristics}

The sample size of these studies ranged from 32 to 798 participants. Two studies focused solely on female employees. Three studies had a majority of female participants (>70\%), while one had a majority of male participants. One study imposed age restrictions on the sample, recruiting only employees over the age of 40 . Three studies recruited staff from universities, two recruited employees from public healthcare organisations and one involved staff from two oil refineries.

The mode of physical activity intervention included walking, aerobics, muscle training and stretching and a choice of medium-to-high intensity exercises. The majority of studies focused on increasing physical activity as the primary outcome measure. One also targeted multiple health behaviours including dietary habits, smoking, sleep etc.

Two studies reported using a sociocultural ecological approach, which centered on environmental level change to inform the design of the interventions. The remaining studies did not mention the theoretical basis of the interventions.

All studies used self-report measures to assess levels of physical activity. One used the International Physical Activity Questionnaire (IPAQ), one used a one-week activity recall questionnaire developed from the Stanford Physical Activity Recall measure, two studies reported developing their own questions to assess exercise habits and two studies asked participants to keep a physical activity diary. These studies also included an objective measure of physical activity, by asking participants to wear an accelerometer or pedometer. Further details about the characteristics of the physical activity/exercise intervention studies are presented in Table 1.

[Insert table one here]

\section{Effect of interventions on physical activity levels}

Findings of the studies in relation to physical activity levels are presented in Table 1. Four of the studies indicated some improvement in physical activity behaviour following the intervention [Coleman et al., 1999; Gilson et al., 2009; Talvi et al., 1999; von Thiele Schwarz et al., 2008]. Two of 
A review of workplace physical activity interventions

these studies showed a statistically significant increase in physical activity levels against a control group (Gilson et al., 2009; von Thiele Schwarz et al., 2008). Gilson et al (2009) found that participants assigned to two different walking conditions showed a significant increase in step counts post intervention compared with a control group $(p<0.01)$. Participants assigned to the workplace walking programme increased their step counts by over 968 steps at the end of the intervention. Participants who were given encouragement to increase their workplace walking also demonstrated an increase of over 699 steps. In comparison, individuals in the control group had decreased their step counts post-intervention. von Thiele et al., (2008) found that participants assigned to an intervention involving 2.5 hours of mandatory workplace physical activity had increased their weekly physical activity by $2-4$ hours following the intervention. In contrast participants assigned to the control group and a comparison group given reduced working hours demonstrated no difference in physical activity levels.

\section{Quality assessment}

Full details of the quality assessment for the six physical activity / exercise interventions are presented in Table 2. Four studies were RCTs, one was a PRT and one was a quasi-experimental study. Of the randomised trials, three randomised to intervention or control group by worksite and two randomised at the individual level. Blinding of the investigator was not mentioned in any of the studies. The use of intention-to-treat analysis was described in one study. Specific eligibility criteria were also reported in one study. Five studies explicitly reported that groups were similar at baseline. One did not take any baseline measures. Half of the studies reported attrition rates; which ranged from $9.2 \%$ to $10 \%$. Two studies did not provide any information about the length of follow-up. In the remaining four studies, length of follow-up ranged from 32 weeks to 3 years.

[Insert table two here]

\section{Counselling/support interventions}


A review of workplace physical activity interventions

A total of thirteen studies were categorised as counselling / support interventions [see table 3].

\section{Study characteristics}

The sample size of studies ranged from 36 to 1880 participants. Two studies focused solely on female employees and two focused solely on male employees. One study had a majority of female participants (>70\%) and one study had a majority of male participants. In the remaining studies the authors either did not provide any information about the gender of the participants or reported a combination of male and female employees. Two studies recruited staff from universities, two recruited staff from fire stations, one involved staff from government departments, and one included participants from both public and private sector organisations. The remaining recruited staff from various mid to large sized companies.

The interventions included individual face-to-face counselling, telephone counselling, counselling and fitness testing, individual and group counselling, group based behavioural skills training and gym membership, counselling and mutual activity sessions, a peer support programme and tailored online magazines, motivational interviewing / counselling versus team-based health promotion classes, face-to-face versus telephone exercise coaching, and telephone versus online counselling. Eight of the interventions targeted multiple health behaviours.

Seven studies mentioned the theoretical basis of the interventions. Four were guided by the Transtheoretical Model with interventions matched to the participant's stage of change. Two studies reported using principles from Social Cognitive Theory to inform the design of the interventions. A combination of theories was used to inform one intervention, including the Transtheoretical Model, Social Cognitive Theory and models of social support.

Self-report measures were used to assess levels of physical activity in all of the studies. Several developed self-report questionnaires for exercise habits. Others used standardised measures of physical activity such as the IPAQ, 7-day physical activity recall questionnaire, the Paffenbarger 
physical activity questionnaire, and the short questionnaire to assess health-enhancing physical activity (SQUASH). Further details about the characteristics of the selected studies are presented in Table 3.

[Insert table three here]

\section{Effect of interventions on physical activity levels}

Findings of the studies in relation to physical activity levels are presented in Table 3. Ten of the studies indicated some improvement in physical activity behaviour following the intervention [Campbell et al., 2002; Elliot et al., 2004; Gold et al., 2000; Heirich et al., 1993; Mackinnon et al., 2010; Nichols et al., 2000; Opdenacker \& Boen, 2008; Proper et al., 2003; Purath et al., 2004; van Wier et al., 2009]. Eight of these studies showed a statistically significant increase in physical activity levels against a control group [Campbell et al., 2002; Elliot et al., 2004; Gold et al., 2000; Heirich et al., 1993; Mackinnon et al., 2010; Nichols et al., 2000; Proper et al., 2003; van Wier et al., 2009]. van Wier et al [2009] found that telephone counselling was more effective at significantly increasing physical activity levels compared to a control group, than an Internet counselling intervention $(p<0.001)$. Similarly, Gold et al [2000] found that participants assigned to a telephone counselling intervention were significantly more likely to reduce their risk in the area of exercise and activity (45.2\% of participants reduced their risk) compared to the employees in the comparison group (26.6\% reduced risk) $(p<0.05)$. Campbell et al (2002) reported that women with access to a tailored computer-based intervention and peer support in the form of trained behaviour change mentors in the workplace; significantly increased their average frequency of strengthening and flexibility exercise compared with the control group. Two studies also found that individual face-to-face counselling $(p<0.01)$ [Heirich et al., 1993] and a behavioural skills intervention $(p<0.10)$ [Nichol et al., 2000] resulted in greater improvements in physical activity habits compared with control conditions, in which participants were given access to free gym and fitness facilities. In fact, Heirich et al [1993] found that while more participants in the two counselling conditions (44 and $45 \%$ ) were exercising 
three times per week or more at follow-up compared with the control group, participants assigned to a staffed physical fitness facility condition, showed a significant decline in the percentage of people engaging in regular exercise at follow-up $(-6 \%)(p<0.01)$. Proper et al (2003) also reported a significant increase in total energy expenditure amongst participants assigned to a tailored individual counselling condition in comparison with the control condition. In contrast, two studies found that a team-based health promotion intervention appeared to be more effective at improving exercise habits at follow-up compared with a control group than a one-to-one counselling intervention $(p<0.05)$ [Elliot et al., 2004; Mackinnon et al., 2010].

\section{Quality assessment}

Full details of the quality assessment are presented in Table 4. Nine studies were RCTs, two were PRTs, and two studies used a quasi-experimental design. Of the randomised trials, six randomised to intervention or control group by worksite and five randomised at the individual level. Blinding of the investigator was not mentioned in any of the studies. The use of intention-to-treat analysis was described in one study. Specific eligibility criteria were reported in eight studies. Four of the studies explicitly reported that groups were similar at baseline. In the remaining nine studies, this information was either omitted or some differences in baseline measures were found between groups. Information on attrition was reported in ten studies. The attrition rates ranged from $1 \%$ to $65 \%$. Length of follow-up was also reported in ten studies and ranged from six weeks to four years. In five of the RCTs, the control groups also received some form of minimal intervention (e.g. lifestyle brochures).

[Insert table four here]

\section{Health promotion messages/information interventions}

The majority (67\%) of included studies were interventions providing health promotion messages / information ( $n=39$ ) [see table five]. 


\section{Study characteristics}

The sample size of the studies varied considerably ranging from 46 to 4894 participants. In terms of gender, two interventions included only female employees and one intervention consisted solely of male participants. There were also seven studies with a majority of female participants $(70 \%>)$ and two had a majority of male participants. In the remaining studies the authors either did not provide any information about the gender of the participants or included a mixture of male and female employees. Five studies recruited staff from a university, three recruited staff from government departments, two from hospitals and three involved employees from different schools. In one study, participants were recruited from three different public sector organisations: a school, a university and a health board. In another, participants came from both a government and commercial organisation. The remaining studies recruited participants from various mid to large sized companies.

The mode of intervention used in the studies varied and included posters promoting stair use, health screening accompanied by targeted health promotion activities, written health promotion materials, email messages, health promotion workshops/classes, web-based health promotion messages, record keeping of physical activities, and multicomponent interventions (e.g. a combination of emails, posters and flyers). Two studies compared the effectiveness of web versus printed health promotion materials. The majority of these interventions were designed to target multiple health behaviours (e.g. promoting healthy eating as well as physical activity).

Twenty-one studies (54\%) mentioned the theoretical basis of the interventions. Fourteen were guided by the Transtheoretical Model with interventions matched to the participant's stage of change. Four studies reported using principles from Social Cognitive Theory to inform the design of the interventions. One study used the Theory of Planned Behaviour and two reported using multiple socio-cognitive theories to inform the intervention including Social Cognitive Theory, Protection Motivation Theory, Stages of Change Model, and the Theory of Planned Behaviour. 
A variety of self-report measures were used to assess levels of physical activity. Most studies $(n=15)$ developed self-report questions for exercise habits. Others used standardised measures of physical activity such as the IPAQ, 7-day physical activity recall questionnaire, the Godin leisure time exercise questionnaire, Stanford Brief Activity Survey (SBAS), the SQUASH, and the Aerobic Centre Longitudinal Study Physical Activity Questionnaire. Four studies also included an objective measure of physical activity by asking participants to wear an accelerometer or pedometer. Further details about the characteristics of the selected studies are presented in Table 5.

[Insert table five here]

\section{Effect of interventions on physical activity levels}

Findings of the studies in relation to physical activity levels are presented in Table 5. Twentynine indicated some improvement in physical activity behaviour following the intervention period [Blair et al, 1986; Blissmer \& McAuley, 2002; Cardinal \& Sachs, 1996; Cook et al, 2001; Cook et al, 2007; Dishman et al, 2009; Emmons et al, 1999; Hager et al, 2002; Hallam \& Petosa, 2004; Hedberg et al, 1999; Kronenfeld et al, 1987; Kwak et al, 2009; Loughlan \& Mutrie, 1997; Morgan et al, 2011; Mutrie et al, 2002; Naito et al, 2008; Napolitano et al, 2003; O'Loughlin et al, 1996; Peterson \& Aldana, 1999; Plotnikoff et al, 2005; Plotnikoff et al, 2007; Robbins et al, 1987; Sherman et al, 1989; Speck \& Looney, 2001; Spittaels et al, 2007; Sorensen et al, 2005; Sternfeld et al, 2009; Titze et al, 2001; Yap et al, 2009]. Twenty-two of these showed a statistically significant increase in physical activity levels against a control [Blair et al, 1986; Blissmer \& McAuley, 2002; Cardinal \& Sachs, 1996; Cook et al, 2001; Dishman et al, 2009; Emmons et al, 1999; Hager et al, 2002; Hallam \& Petosa, 2004; Hedberg et al, 1998; Kwak et al, 2009; Morgan et al, 2011; Mutrie et al, 2002; Naito et al, 2008; Napolitano et al, 2003; O'Loughlin et al, 1996; Peterson \& Aldana, 1999; Plotnikoff et al, 2005; Speck \& Looney, 2001; Sorensen et al, 2005; Sternfield et al, 2009; Titze et al, 2001; Yap et al, 2009].

Six found that interventions with stage-of-change matched health promotion materials showed a significantly greater increase in physical activity levels at follow-up when compared to 
stage mismatched or control conditions [Blissmer \& McAuley, 200; Mutrie et al, 2002; Napolitano et al, 2002; Peterson \& Aldana, 1999; Sternfeld et al, 2009; Yap et al, 2009]. One study reported that participants assigned to both a stage-matched and a stage mismatched email intervention showed a significantly greater increase in their leisure time physical activity post intervention (by $8.6 \%$ and $6.3 \%$ respectively), compared with participants assigned to the control group $(p<0.05)$ [Hager et al, 2002]. Another found that an online intervention incorporating stage-of-change targeted reminder emails, was equally as effective as an online intervention without stage-matched reminder emails and a standard physical activity advice condition in significantly increasing physical activity levels at follow-up ( $p<0.001)$ [Spittaels et al, 2007]. However, in contrast, one study found that stagematched health promotion materials delivered via the web and in a printed format were both ineffective at increasing physical activity [Marshall et al, 2003].

Another study found that an intervention which allowed employees to take an active role in designing and implementing health promotion activities was more effective in improving exercise habits than a standard self-help programme on physical activity $(P<0.05)$ [Emmons et al, 1999]. Cardinal \& Sachs [1996] found that a health promotion packet, which encouraged participants to engage in 30 minutes of physical activity on most days of the week was more effective at increasing weekly leisure time physical activity compared with a health promotion packet that encouraged a gradual increase in the number of weekly exercise sessions $(p<0.01)$.

\section{Quality assessment}

Full details of the quality assessment are presented in Table 6. Eighteen studies were RCTs, three were PRTs and eighteen studies used a quasi-experimental design. Of the randomised trials, eight randomised to intervention or control group by worksite and thirteen randomised at the individual level. Blinding of the investigator was mentioned in three of the studies. The use of intention-to-treat analysis was described in seven studies. Specific eligibility criteria were reported in thirteen studies. Just over a third of the studies $(n=14)$ explicitly reported that groups were similar at 
A review of workplace physical activity interventions

baseline. In the remaining studies, this information was either omitted or some differences in baseline measures were found between groups. Most studies $(n=30)$ provided specific information on attrition. The attrition rates ranged from $4 \%$ to $56 \%$. Length of follow-up was reported in twentyfour studies and ranged from two weeks to five years. In seven of the RCTs, the control groups also received some form of minimal intervention (e.g. information about their health status).

[Insert table six here]

\section{Behaviour Change Techniques (BCTs) in Interventions}

A review of BCTs within intervention descriptions was also carried out. The lack of clear detail provided in some articles made evaluation of BCTs more difficult, therefore only techniques explicitly referenced by authors and agreed on as present by two reviewers have been included in the summary table (see Table 7). The number of techniques identified per study ranged from 0 to 10. In thirteen studies, the research team was unable to identify an explicit BCT from the intervention description. However the majority (67\%) of studies coded multiple BCTs (Mean=3.2). The main BCTs identified in the interventions included: Goal setting (behaviour) (21 studies), Provide instruction on how to perform the behaviour (20 studies), Prompt self-monitoring of behaviour (14 studies), Provide information on where and when to perform the behaviour (13 studies), Plan social support/ social change (12 studies) and Provide information on consequences of behaviour in general (12 studies).

[Insert table seven here]

\section{Discussion}

The purpose of this review was to systematically examine and summarise the evidence on workplace interventions to promote physical activity. In accordance, with the growing public health emphasis on active lifestyles and workplace health and well-being; our findings demonstrate that there is a considerable volume of evidence in this area, including a further 12 studies published since 
the 2008/9 systematic reviews on the same topic [Abraham \& Graham-Rowe, 2009; Dugdill et al., 2008].

Types of interventions

Of the 58 studies included, the majority utilised health promotion initiatives. There were eight physical activity/exercise interventions, thirteen counselling/support interventions, and thirtynine health promotion messages/information interventions. However, the review identified only six studies that included an actual workplace physical exercise component (e.g. aerobic classes or walking groups).

\section{Intervention characteristics}

The majority of studies utilised psychological or behavioural strategies to change people's exercise behaviour. Almost half of the 58 intervention studies were designed to target multiple health behaviours and most targeted both men and women, with several focused mainly on women participants. The mode and delivery of intervention varied considerably across the studies ranging from face-to-face communication, posters, logging of activities, emails, and group exercise.

Several studies in this review drew on the Transtheoretical Model in order to tailor interventions to specific stages of change. However, these studies reported mixed findings. In an earlier meta-analysis of workplace physical activity interventions, Abraham \& Graham-Rowe (2009) concluded that interventions that individually tailored information and feedback were no more effective than interventions providing generic information, and indeed poor outcomes from tailored interventions delivered in the workplace have also been observed in the promotion of other health behaviours [McHugh \& Suggs, 2012]. This pattern of findings is somewhat surprising given that many studies have advocated the tailoring of health education and behaviour change communications and shown positive data trends [Brug et al., 2003; Dijkstra et al., 1999; Kreuter et al., 1999; Suggs, 2003; Suggs 2006]. It is possible that tailored programs are not tailored to the most predictive constructs, 
or that messages alone are not enough to raise physical activity levels via a workplace setting. Indeed, it may be that within a workplace setting, social influences play a greater role in an individual's health behaviour choices than individual factors alone. For example, both Elliot et al [2004] and Mackinnon et al [2010] found that team-based health promotion classes had a more positive impact on physical activity behaviour than individual health counselling.

It is notable that very few of the workplace interventions identified in this review included an actual physical exercise or physical activity component. Of the six physical activity interventions identified, two walking interventions reported a significant increase in physical activity levels following the intervention. This finding is reflective of earlier systematic reviews, which also found some evidence to support the efficacy of workplace walking interventions for promoting overall physical activity levels [Abraham \& Graham-Rowe, 2009; Dugdill et al., 2008]. One explanation for this could be that interventions that provide individuals with an opportunity to engage in physical activity during their working day also help to overcome the commonly cited barrier to exercise participation: lack of time [Dugdill et al., 2008]. Such interventions may help individuals to develop exercising as a healthy habit, which can more readily be maintained following the end of the programme [Verplanken \& Melkevik, 2008].

Impact on physical activity levels

Findings from the current review show that while there are several examples of studies in which a workplace intervention has been successful in increasing certain elements of physical activity behaviour against a control group ( $n=32)$, equally there are a volume of studies in which no difference has been observed or in which both the control and intervention conditions have demonstrated similar increases in levels of physical activity. Consequently, although workplace interventions do show some promise for increasing physical activity, the evidence base for their efficacy is not overwhelmingly strong. In addition, it is unclear from the reviewed studies whether particular types of interventions (e.g. counselling versus exercise interventions) or delivery formats 
A review of workplace physical activity interventions

(e.g. telephone versus internet or individual versus group) are more effective than others. There is also inconclusive evidence regarding the efficacy of tailoring interventions to particular 'stages of change'. While, some studies have shown that stage-matched interventions are more effective than non-stage-matched interventions, other studies found no such effect. Consequently, similar to the findings of the earlier systematic reviews in this area, it appears that firm recommendations about the effectiveness of workplace interventions for increasing physical activity or the types of interventions that show the most promise are still not possible.

\section{Methodological quality of studies}

Most of the studies included were randomised controlled trials. Although the quality of available evidence varies considerably, our quality assessment indicated several common methodological limitations across studies. A key area of concern is related to outcome measurements of physical activity. The majority of the reviewed studies relied solely on self-report measures. Furthermore, many of these used non-validated questionnaires or single items to assess physical activity behaviour. This not only introduces the risk of response bias but can also make direct comparison between studies problematic.

It was also noted that many of the reviewed interventions included multiple heterogeneous components. As a result, the success of particular intervention cannot be attributed to a specific intervention component. In addition, several of the RCTs lacked a true control group, in that control participants were also given some form of minimal intervention. This can potentially obscure the real effectiveness of an intervention for increasing physical activity and may therefore limit generalizability of the findings. However, in some situations it could also be argued that a minimal intervention control group might be more appropriate in a workplace setting (e.g. if the intervention involves co-workers who are randomised at an individual level).

Participation in the interventions was primarily on a voluntary basis. Employees enrolling in the programmes may therefore have had greater motivation to change their health behaviours than 
A review of workplace physical activity interventions

other employees. This is a particular concern in the non-randomised controlled trials, where researchers often compared volunteer participants with non-participants in the same organisation. Unfortunately, in a workplace setting it is often impractical to randomly assign employees to treatment groups. For example, health promotion materials may be exchanged between employees in different treatment groups, thus introducing contamination bias and potentially obscuring the effects of a given intervention. For this reason, many of the RCT studies included in this review randomised at the worksite rather than individual employee level. However, although this is a feasible and practical approach, our review found that participant characteristics in the control and intervention conditions were not always equivalent at baseline. Although, differences at baseline can be taken into account statistically when comparing experimental conditions, this nonetheless introduces the risk of subsequent bias in intervention outcomes, particularly since many studies fail to fully report statistical analyses undertaken and biases in recruitment.

The review found that long-term intervention effects ( $\geq 6$ months after the end of the intervention) were only assessed in a handful of studies. Also, many studies failed to provide sufficient information about length of follow-up. Those studies that did report longer term outcomes also reported high rates of attrition. Despite this, very few of the studies mentioned use of intentionto-treat analyses. It may be that some studies conducted an intention-to-treat analysis but failed to report this in their publication. Thus, it is unclear whether the reported results are only applicable to those who reported for all assessments and there is a possibility that the findings may be subject to selection bias.

\section{Recommendations for future research}

Although there have been twelve more recently published studies which met our criteria, we identified many of the same methodological issues identified in earlier systematic reviews.

Consequently, it can be concluded that despite the recent focus on research in this area there 
remains a need for more well-designed studies to evaluate the effectiveness of workplace interventions with regards to promoting physical activity.

Given the propensity of studies that used non-validated measures to assess physical activity behaviour, future research should endeavour to include valid and reliable self-report measures of both workplace and leisure-time physical activity, and where appropriate use these in conjunction with an objective measure of physical activity (e.g. step counts). That said, there is evidence to suggest that pedometer or accelerometer use may serve as an intervention in itself, and thus make it difficult to know what intervention component served as the prompt to behaviour change [Bravata et al., 2007; Pal et al., 2009; Rooney et al., 2003]. Hence, the use of such devices should be acknowledged as potentially influencing behavioural outcomes. Secondly, given the high rates of attrition reported in several studies, the feasibility and acceptance of different types of workplace interventions should also be explored in future research. This will allow researchers and policy makers to determine whether certain types of interventions are more suited to particular types of organisations.

Future research should also seek to evaluate which theories of behaviour change are of most value when designing workplace physical activity promotion interventions and compare the efficacy of different types and formats of workplace physical activity interventions. Efforts should be made to ensure that physical activity outcomes are assessed at both the end of the intervention and at regular follow-ups to see if any positive intervention effects can be maintained 6-12 months after the end of the intervention.

\section{Limitations}

Limitations to this review should be taken into account when interpreting the findings. First, our literature search was limited to academic articles published in the English language, thus we may have missed some relevant studies published in other languages or in grey literature sources. Our search of academic databases alone resulted in the retrieval of 23,717 article abstracts; the majority 
A review of workplace physical activity interventions

of which were excluded because they did not include a physical activity intervention; future research should therefore consider narrowing the search strategy by including a specific 'intervention' component in the key word search. Second, as with most systematic reviews, there remains a risk of publication bias, as interventions yielding a negative or insignificant outcome are less likely to be published [Dwan et al., 2008]. Finally, due to the heterogeneity of the identified studies, it was not feasible to quantitatively synthesise the results through a meta-analysis. Consequently, we were unable to compare the size of effect across different types of intervention.

\section{Conclusions}

In summary, this systematic review provides a comprehensive overview of research literature pertaining to workplace interventions and physical activity outcomes. Despite the growing body of research in this area, our findings highlight several methodological shortcomings in the current evidence base as identified in previous systematic reviews. Consequently, it remains difficult to draw robust conclusions regarding whether, or which type of, workplace interventions are indeed effective for increasing physical activity among employees. While the studies included in this review do show some evidence that workplace physical activity interventions can be efficacious, overall the results are inconclusive and more work is needed to ascertain which elements of workplace physical activity interventions are most likely to increase efficacy and adoption within the workplace setting. Given the positive outcomes of some of the studies in this field, there is a strong argument for pursuing research efforts in this field to support national and global public health policy to increase physical activity levels in working-age adults. 


\section{References}

Abraham, C., \& Graham-Rowe, E. (2009). Are worksite interventions effective in increasing physical activity? A systematic review and meta-analysis. Health Psychology Review, 3(1), 108-144.

Aittasalo, M., Miilunpalo, S., \& Suni, J. (2004). The effectiveness of physical activity counselling in a work-site setting: a randomized, controlled trial. Patient Education and Counselling, 55(2), 193-202.

Badland, H.M., \& Schofield, G.M. (2005). Posters in a sample of professional worksites have no effect on objectively measured physical activity. Health Promotion Journal of Australia, 16(1), 78-81.

Banbury, P., Neil, C., \& Johnson, E. (2010). The role of exercise in the management of long term pain: a biopsychosocial approach. In H. Blake (Ed.) Physical Activity in Rehabilitation and Recovery (pp. 101-130). New York: NovaScience.

Benedict, M.A., \& Arterburn, D. (2008). Worksite-based weight loss programs: a systematic review of recent literature. American Journal of Health Promotion, 22(6), 408-416.

Bergström, G., Björklund, C., Fried, I., Lisspers, J., Nathell, L., Hermansson, U., Helander, A., Bodin, L., \& Jensen, I.B. (2008). A comprehensive workplace intervention programme and its outcome with regard to lifestyle, health and sick leave: the AHA. Work, 31(2), 167-180.

Blake, H., Mo, P., Malik, S., \& Thomas, S. (2009). How effective are physical activity interventions for alleviating depressive symptoms in older people? A systematic review. Clinical Rehabilitation, 23(10) 873-887.

Blair, S.N., Smith, M., Collingwood, T.R., Reynolds, R., Prentice, M.C., \& Sterling, C.L. (1986). Health promotion for educators: impact on absenteeism. Preventive Medicine, 15(2), 166-175. 
Blissmer, B., \& McAuley, E. (2002). Testing the requirements of stages of physical activity among adults: the comparative effectiveness of stage-matched, mismatched, standard care, and control interventions. Annals of Behavioral Medicine, 24(3), 181-189.

Boudreau, F., Godin, G., Pineau, R., \& Bradet, R. (1995). Health risk appraisal in an occupational setting and its impact on exercise behaviour. Journal of Occupational and Environmental Medicine, 37(9), 1145-1150.

Bravata, D.M., Smith-Spangler, C., Sundaram, V., Gienger, A.L., Lin ,N., Lewis, R., Stave, C.D., Olkin, I., \& Sirard, J.R. (2007). Using pedometers to increase physical activity and improve health: a systematic review. The Journal of the American Medical Association, 298(19), 2296-2304.

Brug, J., Oenema, A., \& Campbell, M. (2003). Past, present, future of computer-tailored nutrition education. American Journal of Clinical Nutrition, 77(4), 10285-10345.

Campbell, M.K., Tessaro, I., DeVellis, B., Benedict, S.., Kelsey, K., Belton, L., \& Sanhueza, . (2002). Effects of a tailored health promotion program for female blue-collar workers: Health works for women. Preventive Medicine, 34(3), 313-323.

Cardinal, B.J., \& Sachs, M.L. (1996). Effects of mail-mediated, stage-matched exercise behavior change strategies on female adults' leisure-time exercise behaviour. Journal of Sports Medicine and Physical Fitness, 36(2), 100-107.

Coleman, K.J., Raynor, H.R., Mueller, D.M., Cerny, F.J., Dorn, J.M., \& Epstein, L.H. (1999). Providing sedentary adults with choices for meeting their exercise goals. Preventive Medicine, 280(5), 510-519.

Cook, C., Simmons, G., Swinburn, B., \& Stewart, J. (2001). Changing risk behaviours for noncommunicable disease in New Zealand working men--is workplace intervention effective? New Zealand Medical Journal, 114(1130), 175-178. 
Cook, R.F., Billings, D.W., Hersch, R.K., Back, A.S., \& Hendrickson, A. (2007). A field test of a webbased workplace health promotion program to improve dietary practices, reduce stress, and increase physical activity: A randomized trial. Journal of Medical Internet Research, 9(2).

De Cocker, K., De Bourdeaudhuij, I., \& Cardon, G. (2010). The effect of a multi-strategy workplace physical activity intervention promoting pedometer use and step count increase. Health Education Research, 25(4), 608-619.

Department of Health. (2004). At least five a week: evidence on the impact of physical activity and its relationship to health. London: UK.

Department of Health. (2008). 'Working for a healthier tomorrow' - Dame Carol Black's review of the health of Britain's working age population. London: UK

Department of Health. (2009). Let's get moving: a new physical activity care pathway for the NHS, commissioning guidance. London: UK.

Department of Health. (2011). Start active, stay active: a report on physical activity for health from the four home countries Chief Medical Officers. London: UK.

Department for Work and Pensions, Department of Health \& the Health and Safety Executive. (2005). Health, work and well-being - caring for our future: a strategy for the health and well-being of working age people. London: UK.

Dijkstra, A., De Vries, H.D., \& Roijackers, J. (1999). Targetting smokers with low readiness to change with tailored and non-tailored self-help materials. Preventive Medicine, 28(2), 203-211.

Dishman, R.K., DeJoy, D.M., Wilson, M.G., \& Vandeberg, R.J. (2009). Move to improve: a randomised workplace trial to increase physical activity. American Journal of Preventive Medicine, 36(2), 133141. 
Dishman, R.K., Oldenburg ,B., O’Neal, H., \& Shepard, R.J. (1998). Worksite physical activity interventions. American Journal of Preventive Medicine, 15(4), 344-361.

Dugdill, L., Brettle, A., Hulme, C., McCluskey, S., \& Long, A.F. (2008). Workplace physical activity interventions: a systematic review. International Journal of Work Health Management, 1(1), 20-40.

Dwan, K., Altman, D.G., Arnaiz, J.A., Bloom, J., Chan, A.W., Cronin, E., Decullier, E., Easterbrook, P.J., Von Elm, E., Gamble, C., Ghersi, D., Ioannidis, J.P., Simes, J., \& Williamson, P.R. (2008). Systematic review of the empirical evidence of study publication bias and outcome reporting bias. PloS One, 3(8), e3081.

Elliot, D.L., Goldberg, L., Duncan, T.E., Kuehl, K.S., Moe, E.L., Breger, R.K., DeFrancesco, C.L., Ernst, D.B., \& Stevens, V.J. (2004). The PHLAME Firefighters' Study: Feasibility and Findings. American Journal of Health Behavior, 28(1), 13-23.

Emmons, K.M., Linnan, L.A., Shadel, W.G., Marcus, B., \& Abrams, D.B. (1999). The Working healthy project: a worksite health promotion trial targeting physical activity, diet and smoking. Journal of Occupational and Environmental Medicine, 41(7), 545-555.

Fine, L.J., Philogene, G.S., Gramling, R., Coups, E.J., \& Sinha, S. (2004). Prevalence of multiple chronic disease risk factors: 2001 National Health Interview Survey. American Journal of Preventive Medicine, 27(2), 18-24.

French, S.A., Harnack, L.J., Hannan, P.J., Mitchell, N.R., Gerlach, A.F., \& Toomey, T.L. (2010). Worksite environment to prevent obesity among metropolitan transit workers. Preventive Medicine, 50(4), 180-185.

Fox, K.R. (1999). The influence of physical activity on mental well-being. Public Health Nutrition, 2(3a), 411-418. 
Gilson, N.D., Puig-Ribera, A., McKenna, J., Brown, W.J., Burton, N.W., \& Cooke, C.B. (2009). Do walking strategies to increase physical activity reduce reported sitting in workplaces: a randomized control trial. International Journal of Behavioral Nutrition and Physical Activity,20(6), 43.

Gold, D.B., Anderson, D.R., \& Serxner, S.A. (2000). Impact of a telephone-based intervention on the reduction of health risks. American Journal of Health Promotion, 15, 97-106.

Hager, R.L., Hardy, A., Aldana, S.G., \& George, J.D. (2002). Evaluation of an Internet, stage-based physical activity intervention. American Journal of Health Education, 33(6), 328-335.

Hallam, J., \& Petosa, R. (1998). A worksite intervention to enhance social cognitive theory constructs to promote exercise adherence. American Journal of Health Promotion, 13(1), 4-7.

Health, Work Wellbeing: Improving health and work: changing lives. (2008). The Policy Response to Dame Carol Black's Review of the health of Britain's working age population. London: UK.

Hedberg, G.E., Wikstrom-Frisen, L., \& Janlert, U. (1998). Comparison between two programmes for reducing levels of risk indicators of heart diseases among male professional drivers. Occupational and Environmental Medicine, 55(8), 554-561.

Heirich, M.A., Foote, A., Erfurt, J.C., \& Konopka, B. (1993). Work-site physical fitness programs: comparing the impact of different program designs on cardiovascular risks. Journal of Occupational Medicine, 35(5), 510-517.

Jeon, C.Y., Lokken, P.R., Hu, F.B., \& van Dam, R.M. (2007). Physical activity of moderate intensity and risk of Type 2 Diabetes: a systematic review. Diabetes Care, 30(3), 744-752.

Katzmarzyk, P.T., \& Janssen, I. (2004). The economic costs associated with physical inactivity and obesity in Canada: an update. Canadian Journal of Applied Physiology, 29(1), 90-115.

Kreuter, M.W., Strecher, V.J., \& Glassman, B. (1999). One size does not fit all: the case for tailoring print materials. Annals of Behavioral Medicine, 21(4), 276-283. 
Kronenfeld, J.J., Jackson, K., Blair, S.N., Davis, K., Gimarc, J.D., Salisbury, Z., Maysey, D., \& McGee, J.G. (1987). Evaluating health promotion: A longitudinal quasi-experimental design. Health Education Quarterly, 14(2), 123-139.

Kwak, L., Kremers, S.P., Visscher, T.L., van Baak, M.A., \& Brug, J. (2009). Behavioral and cognitive effects of a worksite-based weight gain prevention program: The NHF-NRG In Balance-project. Occupational and Environmental Medicine, 51(12), 1437-1446.

Lee, C., \& White, S.W. (1997). Controlled trial of a minimal-intervention exercise program for middleaged working women. Psychology and Health, 12(3), 361-374.

Loughlan, C.,\& Mutrie, N. (1997). An evaluation of the effectiveness of three interventions in promoting physical activity in a sedentary population. Health Education Journal, 56(2), 154-165.

Marshall, A.L., Leslie, E.R., Bauman, A.E., Marcus, B.H. \& Owen, N. (2003). Print versus website physical activity programs: a randomized trial. American Journal of Preventive Medicine, 25(2), 8894.

MacKinnon, D.P., Elliot, D.L., Thoemmes, F., Kuehl, K.S., Moe, E.L., Goldberg, L., Burrell, G.L.,\& Ranby, K.W. (2010). Long-term effects of a worksite health promotion program for firefighters. American Journal of Health Behavior, 34(6):695-706.

McEachan, R.R., Lawton, R.J., Jackson, C., Conner, M., Meads, D.M., \& West, R.M. (2011). Testing a workplace physical activity intervention: a cluster randomised controlled trial. International Journal of Behaviour Nutritional and Physical Activity, 8(29).

Medibank. (2007). The cost of physical inactivity: what is the lack of participation in physical activity costing Australia. Retrieved February 13, 201, from http://www.medibank.com.au/Client/Documents/Pdfs/pyhsical inactivity.pdf 
McHugh, J., \& Suggs, L.S. (2012). Online Tailored Weight Management in the Worksite: Do They Make a Difference in Biennial HRA Data? Journal of Health Communication: International Perspectives. 17(3) p. 278-293.

Michie, S., Ashford, S., Sniehotta, F.F., Dombrowski, S.U., Bishop, A., \& French, D.P. (2011). A refined taxonomy of behaviour change techniques to help people change their physical activity and healthy eating behaviours: The CALO-RE taxonomy. Psychology and Health, 26(11), 1479-1498.

Mora, S., Cook, N., Buring, J.E., Ridker, P.M., \& Lee, I.M. (2007). Physical activity and reduced risk of cardiovascular events: potential mediating mechanisms. Circulation, 116(19), 2110-2118.

Morgan, P.J., Collins, C.E., Plotnikoff, R.C., Cook, A.T., Berthon, B., Mitchell, S., \& Callister, R. (2011). Efficacy of a workplace-based weight loss program for overweight male shift workers: The Workplace POWER (Preventing Obesity Without Eating like a Rabbit) randomized controlled trial. Preventive Medicine 52(5), 317-325.

Moy, F., Sallam, A.A., \& Wong, M. (2006). The results of a worksite health promotion programme in Kuala Lumpur Malaysia. Health Promotion International, 21(4), 301-310.

Mutrie, N., Carney, C., Blamey, A., Crawford, F., Aitchison, T., \& Whitelaw, A. (2002). "Walk in to Work Out": a randomised controlled trial of a self-help intervention to promote active commuting. Journal of Epidemiology \& Community Health, 56(6), 407-412.

Naito, M., Nakayama, T., Okamura, T., Miura, K., Yanagita, M., Fujieda, Y., Kinoshita, F., Naito, Y., Nakagawa, H., Tanaka, T., \& Ueshima, H. (2008). Effect of a 4-year workplace-based physical activity intervention program on the blood lipid profiles of participating employees: the high-risk and population strategy for occupational health promotion (HIPOP-OHP) study. Atherosclerosis, 197(2), 784-790. 
Napolitano, M.A., Fotheringham, M., Tate, D., Sciamanna, C., Leslie, E., Owen, N., Bauman, A., \& Marcus, B. (2003). Evaluation of an internet-based physical activity interntion: A preliminary intervention. Annals of Behavioral Mediciine, 25(2), 92-99.

National Institute for Health and Clinical Excellence. (2008). Workplace health promotion: how to encourage employees to be physically active. London: UK.

NHS information Centre (2008). Healthy Survey for England: Physical Activity and Fitness. Retrieved January 4, 2012, from http://www.ic.nhs.uk/pubs/hse08physicalactivity.

Nichols, J.F., Wellman, E., Caparosa, S., Sallis, J.F., Calfas, K.J., \&Rowe, R. (2000). Impact of a worksite behavioral skills intervention. American Journal of Health Promotion 14(4), 218-221.

Nisbeth, O., Klausen, K., \& Andersen, L.B. (2000) Effectiveness of counselling over 1 year on changes in lifestyle and coronary heart disease risk factors. Patient Education and Counselling, 400(2), 12131.

Oldridge, N.B. (2008). Economic burden of physical inactivity: healthcare costs associated with cardiovascular disease. European Journal of Cardiovascular Prevention and Rehabilitation, 15(2), 130-139.

O'Loughlin, J., Renaud, L., Paradis, G., \& Meshefedjian, G. (1996). Screening school personnel for cardiovascular disease risk factors: short-term impact on behavior and perceived role as promoters of heart health. Preventive Medicine, 25(6), 660-667.

Opdenacker, J., \& Boen, F. (2008). Effectiveness of face-to-face versus telephone support in increasing physical activity and mental health among university employees. Journal of Physical Activity and Health, 5(6), 830-843.

Ostwald, S.K. (1989). Changing employees' dietary and exercise practices: an experimental study in a small company. Journal of Occupational Medicine, 31(2), 90-97. 
Pal, S., Cheng, C., Egger, G., Binns, C., \& Donovan, R. (2009). Using pedometers to increase physical activity in overweight and obese women: a pilot study. BMC Public Health, 9(309).

Paluska, S.A., \& Schwenk, T. (2000). Physical activity and mental health: current concepts. Sports Medicine, 29(3), 167-180.

Peterson, T.R., \& Aldana, S.G. (1999). Improving exercise behavior: an application of the stages of change model in a worksite setting, American Journal of Health Promotion, 13(4), 229-232.

Plotnikoff, R.C., McCargar, L.J., Wilson, P.M., \& Loucaides, C.A. (2005). Efficacy of an E-mail intervention for the promotion of physical activity and nutrition behavior in the workplace context. American Journal of Health Promotion, 19(6), 422-429.

Proper, K.I., Hildebrandt, V.H., Van der Beek, A.J., Twisk, J.W.R. \&Van Mechelen, W. (2003). Effect of individual counselling on physical activity fitness and health: a randomized controlled trial in a workplace setting. American Journal of Preventive Medicine, 24(3), 218-226.

Plotnikoff, R.C., Brunet, S., Courneya, K.S., Spence, J.C., Birkett, N.J., Marcus, B., \& Whiteley, J. (2007). The efficacy of stage-matched and standard public health materials for promoting physical activity in the workplace: The Physical Activity Workplace Study (PAWS). American Journal of Health Promotion, 21(6), 501-509.

Proper, K.I., Staal, B.J., Hildebrandt, V.H., van der Beek, A.J., \& van Mechelen, W. (2002). Effectiveness of physical activity programs at worksites with respect to work-related outcomes. Scandinavian Journal of Work Environment and Health, 28(2), 75-84.

Purath, J., Miller, A.M., McCabe, G., \& Wilbur, J. (2004). A brief intervention to increase physical activity in sedentary working women. Canadian Journal of Nursing Research, 36(1), 76-91.

Robbins, S., Coogle, C., \& Link-Mullison, M. (1987). The Utility of Brief Health Promotion Workshops. Health Education, 18(4), 36-38. 
Rooney, B., Smalley, K., Larson, J., \& Havens, S. (2003). Is knowing enough? Increasing physical activity by wearing a pedometer. Wisconsin Medical Journal, 102(4), 31-36.

Scottish Intercollegiate Guidelines Network (SIGN). (2011).SIGN Methodological Principles.

Retrieved March 1, 2012, from http://www.sign.ac.uk/methodology/index.html.

Sherman, J.B., Clark, L., \& McEwen, M.M. (1989). Evaluation of a worksite wellness program: impact on exercise, weight, smoking, and stress. Public Health Nursing, 6(3), 114-119.

Siegel, J.M., Prelip, M.L., Erausquin, J.T., Kim, S.A. (2010). A Worksite Obesity Intervention: Results from a group randomized trial. American Journal of Public Health, 100(2), 327-333.

Sjöström, M., Oja, P., Hagströmer, M., Smith, B.J., \& Bauman, A. (2006). Health enhancing physical activity across European Union countries: the Eurobarometer study. Journal of Public Health, 14,291300

Sorensen, G., Barbeau, E., Stoddard, A.M., Hunt, M.K., Kaphingst, K., \& Wallace, L. (2005). Promoting behavior change among working-class, multi-ethnic workers: Results of the Healthy Directions Small Business Study. American Journal of Public Health, 95(8), 1389-1395.

Speck, B.J., \& Looney, S.W. (2001). Effects of a minimal intervention to increase physical activity in women: daily activity records. Nursing Research, 50(6), 374-378.

Spittaels, H., De Bourdeaudhuij, I., Brug, J., \& Vandelanotte, C. (2007). Effectiveness of an online computer-tailored physical activity intervention in a real-life setting. Health Education Research, 22 (3), 385-396.

Sternfeld, B., Block, C., Quesenberry, C.P., Block, T.J., Husson, G., Norris, J.C., Nelson, M., \& Block, G. (2009). Improving diet and physical activity with ALIVE: a worksite randomized trial. American Journal of Preventive Medicine, 26(6), 475-483. 
Stonecipher, L.J., \& Hyner, G.C. (1993). The effects of a comprehensive health risk appraisal, basic screening, and interpretation session on employee health practices: differences between participants and nonparticipants. American Journal of Health Promotion, 7(3), 167-169.

Suggs, L.S. (2003). Analysis \& Perspective: The Case for Tailored Behavior Change Programs. HealthPlan and Provider Report, 9(50),1336-1339.

Suggs, L.S. (2006). A 10-Year Retrospective of Research in New Technologies for Health Communication. Journal of Health Communication: International Perspectives. 11(1). p. 61-74.

Talvi, A.I., Jarvisalo, J.O., \& Knuts, L.R. (1999). A health promotion programme for oil refinery employees: changes of health promotion needs observed at three years. Occupational Medicine, 49(2), 93-101.

The U.S National Physical Activity Plan (2010). Public Health: National Physical Activity Plan. Retrieved March 1, 2012, from http://www.physicalactivityplan.org/pubhealth.php, 2010.

Titze, S., Martin, B.W., Seiler, R., Stronegger, W., \& Marti, B. (2001). Effects of a lifestyle physical activity intervention on stages of change and energy expenditure in sedentary employees. Psychology of Sport and Exercise, 2(2), 103-116.

Verplanken, B., \& Melkevik, O. (2008). Predicting habit: the case of physical exercise. Psychology of Sport and Exercise, 9(1), 15-26.

von Thiele Schwarz, U., Lindfors P., \& Lundberg, U. (2008). Health-related effects of worksite interventions involving physical exercise and reduced workhours. Scandinavian Journal of Work, Environment and Health, 34(3), 179-188.

van Wier, M.F., Ariëns, G.A,, Dekkers, J.C., Hendriksen, I.J., Smid, T., \& van Mechelen, W. (2009). Phone and email counselling are effective for weight management in an overweight working population: a randomized controlled trial. BMC Public Health, 9(6). 
Warburton, D.E.R., Nicol, C.W., \& Bredin, S.S.D. (2006). Health benefits of physical activity: the evidence. Canadian Medical Association Journal, 174(6), 801-809.

World Health Organisation (WHO)/World Economic Forum. (2008). Preventing non-communicable disease in the workplace through diet and physical activity. Geneva: Switzerland.

World Health Organisation (WHO). (2012). Global Strategy on Diet, Physical Activity \& Health. Physical Activity and Adults Recommended levels of physical activity for adults aged 18 - 64 years. Geneva: Switzerland.

Yancey, A.K., McCarthy, W.J., Taylor. W.C., Merlo, A., Gewa, C., Weber, M.D., \& Fielding, J.E. (2004). The Los Angeles Lift Off: a sociocultural environmental change intervention to integrate physical activity into the workplace. Preventive Medicine, 38(6), 848-856.

Yap, T.L., Davis, L.S., Gates, D., Hemmings, A., \& Pan, W. (2009). The effect of tailored e-mails in the workplace: Part II. Increasing overall physical activity. Journal of the American Association of Occupational Health Nurses, 57(8), 313-319. 